\title{
Adubação nitrogenada em milho e capim-xaraés sob plantio direto e preparo convencional em sistema agrossilvipastoril
}

\author{
Maísa Pinto Bravin ${ }^{(1)}$ e Tadário Kamel de Oliveira(2) \\ (1)Universidade Federal do Acre, Programa de Pós-graduação em Produção Vegetal, BR 364, Km 04, Distrito Industrial, CEP 69920-900 Rio Branco, \\ AC, Brasil. E-mail: maisabravin@gmail.com (2)Embrapa Acre, Rodovia BR-364, Km 14, Caixa Postal 321, CEP 69900-970 Rio Branco, AC, Brasil. \\ E-mail: tadario.oliveira@embrapa.br
}

\begin{abstract}
Resumo - O objetivo deste trabalho foi avaliar o desempenho agronômico das culturas do milho e do capim-xaraés (Urochloa brizantha 'Xaraés') em consórcio, cultivadas em plantio direto e convencional, em sistema agrossilvipastoril, com a aplicação de diferentes doses de nitrogênio em cobertura. O experimento foi conduzido em área de cultivo de milho com a espécie florestal mulateiro (Calycophyllum spruceanum). Utilizou-se o delineamento experimental de blocos ao acaso, com arranjo em parcelas subdivididas, com dois sistemas de manejo do solo (plantio direto e convencional com grade pesada) alocados nas parcelas e com cinco doses de adubação nitrogenada em cobertura $\left(0,50,100,150\right.$ e $\left.200 \mathrm{~kg} \mathrm{ha}^{-1} \mathrm{de} \mathrm{N}\right)$, nas subparcelas, o que totalizou dez tratamentos. A produtividade de grãos de milho respondeu linearmente à aplicação de $\mathrm{N}$ em área de plantio convencional. Em área de plantio direto, a dose de $165 \mathrm{~kg} \mathrm{ha}^{-1} \mathrm{de} \mathrm{N} \mathrm{em} \mathrm{cobertura} \mathrm{foi} \mathrm{necessária}$ para a obtenção de produtividades satisfatórias. A adubação nitrogenada em cobertura na cultura do milho, até a dose de $200 \mathrm{~kg} \mathrm{ha}^{-1}$ de $\mathrm{N}$, não influencia o rendimento do capim-xaraés em consórcio nas entrelinhas, após a colheita do milho.
\end{abstract}

Termos para indexação: Brachiaria brizantha, Zea mays, adubação de cobertura, consórcio, integração lavoura-pecuária, manejo do solo.

\section{Nitrogen fertilization in maize and xaraés palisade grass under no-tillage and conventional tillage in an agrosilvopastoral system}

\begin{abstract}
The objective of this work was to evaluate the agronomic performance of the maize and xaraés palisade grass (Urochloa brizantha 'Xaraés') crops in intercropping, grown in no-tillage and conventional tillage, in an agrosilvopastoral system, with the application of different nitrogen topdressing rates. The experiment was conducted in a maize crop area with the forest species "mulateiro" (Calycophyllum spruceanum). The experimental design was randomized complete blocks, in a split-plot arrangement with two systems of soil management (no-tillage and conventional tillage with heavy disk) allocated to the plots and five rates of nitrogen topdressing $\left(0,50,100,150\right.$, and $\left.200 \mathrm{~kg} \mathrm{ha}^{-1} \mathrm{~N}\right)$ to the subplots, totaling ten treatments. Maize grain yield responded linearly to $\mathrm{N}$ application in area of conventional tillage. In no-tillage area, the dose of $165 \mathrm{~kg} \mathrm{ha}^{-1} \mathrm{~N}$ topdressing was necessary to obtain satisfactory yields. Nitrogen topdressing in maize crop until the dose of $200 \mathrm{~kg} \mathrm{ha}^{-1} \mathrm{~N}$ does not influence xaraés palisade grass yield when intercropped between the lines, after maize harvest.
\end{abstract}

Index terms: Brachiaria brizantha, Zea mays, topdressing, intercropping, crop-livestock integration, soil management.

\section{Introdução}

Atualmente, diversas áreas cultivadas com pastagem apresentam sinais de degradação e baixa produtividade. A área cultivada com pastagens no Brasil, em 2009, era de aproximadamente 100 milhões de hectares, dos quais $80 \%$ apresentavam algum estágio de degradação e 50\%, um grau avançado (Barducci et al., 2009). O comprometimento da longevidade produtiva da forragem pode estimular o desmatamento de novas áreas de floresta para a formação de pastagens (Dias-Filho, 2011), o que torna desejável que as pastagens cultivadas tenham sua capacidade produtiva restabelecida. Ao mesmo tempo, as áreas de produção de grãos são cada vez mais aproveitadas durante o ano agrícola, o que faz da integração de sistemas de cultivo uma opção técnica e economicamente viável de produção. 
Uma alternativa para a recuperação de pastagens degradadas, simultânea ao cultivo de grãos e árvores, é a implantação de diferentes modelos de integração lavoura-pecuária-floresta (ILPF). Uma das modalidades de ILPF são os sistemas agrossilvipastoris, que consistem no cultivo simultâneo de plantas produtoras de grãos, árvores e forrageiras na mesma área, o que permite aumentar a produtividade, a estabilidade econômica e a diversidade das culturas (Franzluebbers, 2007) e, também, recuperar as áreas de pastagens degradadas com baixas produtividades.

A escolha das espécies que comporão o sistema de integração tem relação direta com a viabilidade da atividade. As espécies arbóreas devem ter rápido estabelecimento e copa pouco adensada, e as espécies agrícolas e forrageiras devem apresentar tolerância às condições do cultivo, pois a concorrência por luminosidade, água e nutrientes pode afetar o componente agrícola e resultar em perdas de produtividade (Vieira \& Schumacher, 2011; Vilela et al., 2011).

A cultura do milho apresenta destaque em áreas de ILPF, uma vez que a integração com a forrageira proporciona aumento da oferta de palhada para a manutenção do plantio direto, com possibilidade de obtenção de produtividade de grãos satisfatória. Barducci et al. (2009) afirmam que a espécie forrageira implantada no consórcio é decisiva para a obtenção de boas produtividades, tanto de grãos quanto de acúmulo de matéria seca da forragem. Assim, as espécies forrageiras do gênero Urochloa (Syn. Brachiaria) são mais aptas ao cultivo integrado. Isso porque, desde que manejadas adequadamente, não interferem ou tem pouca influência na produção do milho, apresentam boa capacidade de recuperação e formação de pastagem, e contribuem para a redução dos custos com a alimentação animal durante o período de estiagem (Silva et al., 2008; Tracy \& Zhang, 2008).

Junto com o emprego de práticas conservacionistas, como o sistema plantio direto, a ILPF em áreas degradadas proporciona melhoria das propriedades físicas, químicas e biológicas do solo (Macedo, 2009), o que resulta em ganhos de produtividade dos componentes agrícola, florestal e pecuário. Esse sistema de cultivo propicia cobertura eficiente do solo no decorrer do ano e aumento das taxas de matéria orgânica, além de tornar viável o cultivo no sistema plantio direto.
A adoção do cultivo em sistemas conservacionistas, com diferentes modelos de consorciação e rotação de culturas dentro da ILPF, e as condições de cultivo local tornam variável a demanda por adubação nitrogenada, especialmente em cultivos integrados com gramíneas (Borghi \& Crusciol, 2007). As culturas do milho e da braquiária, em cultivo solteiro ou consorciado, são altamente exigentes em nitrogênio, em razão das características intrínsecas das espécies, o que torna esse nutriente limitante da produção quando não suprido de forma adequada durante os estádios cruciais de desenvolvimento das espécies consorciadas (Costa et al., 2012).

O objetivo deste trabalho foi avaliar o desempenho agronômico das culturas do milho e do capim-xaraés (Urochloa brizantha 'Xaraés') em consórcio, cultivadas em plantio direto e convencional, em sistema agrossilvipastoril, com a aplicação de diferentes doses de nitrogênio em cobertura.

\section{Material e Métodos}

O experimento foi conduzido na safra 2012/2013, em condições de campo, no Município de Senador Guiomard, AC (951'26"S, 67²5'42"W, a $181 \mathrm{~m}$ de altitude). O clima da região, conforme a clasificação de Koeppen, é do tipo Af, equatorial, com temperatura média anual de aproximadamente $25^{\circ} \mathrm{C}$ e precipitação anual de até $2.000 \mathrm{~mm}$ (Acre, 2010).

Antes da instalação do experimento, a área encontrava-se, há quatro anos, em sistema silviagrícola, com a espécie florestal mulateiro [Calycophyllum spruceanum (Benth.) K.Schum.] cultivada em linha simples, no espaçamento $20 \times 4 \mathrm{~m}$, com altura e diâmetro a altura do peito médios das árvores de $6,8 \mathrm{e}$ $0,1 \mathrm{~m}$, respectivamente. Nas entrelinhas do mulateiro, foi cultivado o milho, em plantio direto, nas duas últimas safras.

O solo da área experimental é um Argissolo Vermelho distrófico, e os atributos químicos na camada de 0 a $20 \mathrm{~cm}$ do solo, antes da instalação do experimento, foram: $\mathrm{pH}$ em $\mathrm{H}_{2} \mathrm{O}$ de 5,3; 8,8 $\mathrm{g} \mathrm{dm}^{-3}$ de matéria orgânica; $2,03 \mathrm{cmol}_{\mathrm{c}} \mathrm{dm}^{-3} \mathrm{de} \mathrm{H}+\mathrm{Al} ; 5,82 \mathrm{mg}$ $\mathrm{dm}^{-3} \mathrm{de} \mathrm{P}$ (Mehlich 1); 25,32 $\mathrm{mg} \mathrm{dm}^{-3}$ de $\mathrm{P}_{\text {rem }} ; 0,09,3,97$ e 4,71 $\mathrm{cmol}_{\mathrm{c}} \mathrm{dm}^{-3} \mathrm{de} \mathrm{K}^{+}, \mathrm{Ca}^{2+}+\mathrm{Mg}^{2+}$, respectivamente; e $74,3 \%$ de $\mathrm{V}$.

Utilizou-se o delineamento experimental de blocos ao acaso, com quatro repetições, em arranjo de parcelas 
subdivididas, com o tipo de manejo do solo (plantio direto e plantio convencional) nas parcelas e as doses de adubação nitrogenada em cobertura $(0,50,100,150$ e $200 \mathrm{~kg} \mathrm{ha}^{-1}$ de N) nas subparcelas, o que totalizou dez tratamentos. A área experimental foi composta por 40 subparcelas de $8 \times 9 \mathrm{~m}$, com dez linhas de milho, e a área útil correspondeu aos $4 \mathrm{~m}$ centrais das terceira, quarta, sétima e oitava linhas de milho; foram avaliadas as linhas de milho próximas e distantes das árvores de mulateiro.

Antes da instalação do experimento, foram coletadas amostras de biomassa sobre o solo para avaliação da quantidade de matéria seca da palhada presente na área, que correspondeu a $6,78 \mathrm{Mg} \mathrm{ha}^{-1}$. Posteriormente, foi realizado o manejo do solo, com uso de grade pesada e grade niveladora, no sistema convencional e no plantio direto, com aplicação do herbicida glifosato para dessecar a vegetação, na dose de $6 \mathrm{~L} \mathrm{ha}^{-1}$ do produto comercial.

Ohíbrido simples AG 7088PRO de milho foi semeado mecanicamente por meio de semeadora-adubadora, na primeira quinzena de novembro de 2012, com espaçamento de $0,90 \mathrm{~m}$ e seis sementes por metro. Para a adubação de base no sulco de plantio, foi utilizada a fórmula NPK 8-20-20 na dose de $255 \mathrm{~kg} \mathrm{ha}^{-1}$.

A adubação de cobertura foi realizada quando as plantas de milho atingiram o estádio fenológico V6, com seis folhas desenvolvidas, 17 dias após a semeadura. $\mathrm{O}$ adubo nitrogenado utilizado foi a ureia $(45 \%$ de $\mathrm{N})$, e a aplicação foi feita manualmente próximo à linha do milho na superfície do solo, tendose aplicado as doses de 0, 50, 100, 150 e $200 \mathrm{~kg} \mathrm{ha}^{-1} \mathrm{de}$ $\mathrm{N}$ nas subparcelas.

A semeadura da forrageira na entrelinha do milho foi realizada sete dias após a adubação de cobertura, no estádio fenológico V10 do milho. A espécie forrageira utilizada foi o capim-xaraés. A semeadura foi realizada a lanço e manualmente, com taxa de semeadura de $10 \mathrm{~kg} \mathrm{ha}^{-1}$ de sementes puras viáveis.

No período de pleno florescimento, após a emissão da inflorescência feminina, foram realizadas leituras indiretas do teor de clorofila foliar (índice SPAD), com clorofilômetro digital Minolta SPAD-502 (Konica Minolta Sensing Americas, Inc., Ramsey, NJ, EUA). As leituras foram realizadas no terço médio da folha-índice - a primeira abaixo da espiga -, em dois pontos da folha, na parte central e a $2 \mathrm{~cm}$ da margem, tendo-se avaliado dez folhas por subparcela.
No mesmo dia, mediu-se a altura de plantas de milho com auxílio de régua graduada do solo até a base de inserção da última folha.

A colheita do milho foi realizada aos 120 dias após a semeadura, quando as espigas atingiram ponto de colheita, com umidade dos grãos inferior a $25 \%$. A colheita foi feita manualmente na área útil das parcelas, e as espigas foram levadas a um galpão de secagem, para realização das avaliações de pós-colheita. Para o milho, foram avaliados os seguintes componentes de produção: número de grãos por fileira e número de grãos por espiga, em 20 espigas por subparcela; massa de 100 grãos e massa de grãos por espiga, corrigidos para 13\% de umidade (Secagem de sementes, 1987), com uso da equação: peso final $=$ peso inicial $\times(100$ - umidade inicial) / (100 - umidade final).Os dados de produtividade de grãos foram convertidos para $\mathrm{kg} \mathrm{ha}^{-1}$ de grãos de milho com teor de umidade ajustado para 13\% (Secagem de sementes, 1987).

Também foram avaliadas a massa de matéria seca de plantas invasoras e do capim-xaraés na colheita do milho, em área de $0,25 \mathrm{~m}^{2}$, no nível do solo; e a matéria seca do capim-xaraés aos 50, 90 e 145 dias após a colheita do milho, em área de $0,25,0,25$ e $0,50 \mathrm{~m}^{2}$, respectivamente, a $15 \mathrm{~cm}$ do nível do solo.

Os dados coletados foram submetidos à verificação dos pressupostos da análise de variância, pelos testes de Shapiro-Wilk e Bartlett. Em seguida, realizou-se análise de variância, e as médias foram comparadas em função dos preparos do solo, pelo teste $\mathrm{F}$, a $5 \%$ de probabilidade. $\mathrm{O}$ efeito de doses de $\mathrm{N}$ em cobertura foi avaliado por análise de regressão polinomial. Para o processamento dos dados, foram utilizados os programas Excel e Sisvar (Ferreira, 2011).

\section{Resultados e Discussão}

Os sistemas de manejo do solo (plantio direto e convencional) e as doses de nitrogênio em cobertura, na cultura do milho, causaram efeito isolado ou combinado nas variáveis avaliadas.

A altura de plantas foi influenciada pelos manejos do solo, pelas doses de $\mathrm{N}$ em cobertura e pela interação entre ambos (Figura 1). Plantas de milho nos sistemas de plantio convencional e de plantio direto não apresentaram diferença significativa quanto à altura, exceto quando não foi realizada adubação nitrogenada em cobertura. Em plantio direto, as plantas provavelmente sofreram os efeitos da imobilização do 
$\mathrm{N}$ pelos microrganismos que atuam na decomposição da matéria orgânica (MO) do solo, o que resultou em plantas com menor altura nesse tratamento. Em áreas de plantio direto recém implantadas, há ocorrência de altas taxas de imobilização de $\mathrm{N}$ por microrganismos que atuam na decomposição do material orgânico (Argenta et al., 2003). No plantio direto, as maiores plantas $(2,31 \mathrm{~m})$ foram obtidas com uso de $137,5 \mathrm{~kg} \mathrm{ha}^{-1}$ de $\mathrm{N}$ em cobertura. Resultado diferente foi observado no plantio convencional, em que as alturas das plantas de milho responderam linearmente às doses de $\mathrm{N}$ (Figura 1), possivelmente em razão do revolvimento do solo com grade que acelera a decomposição dos
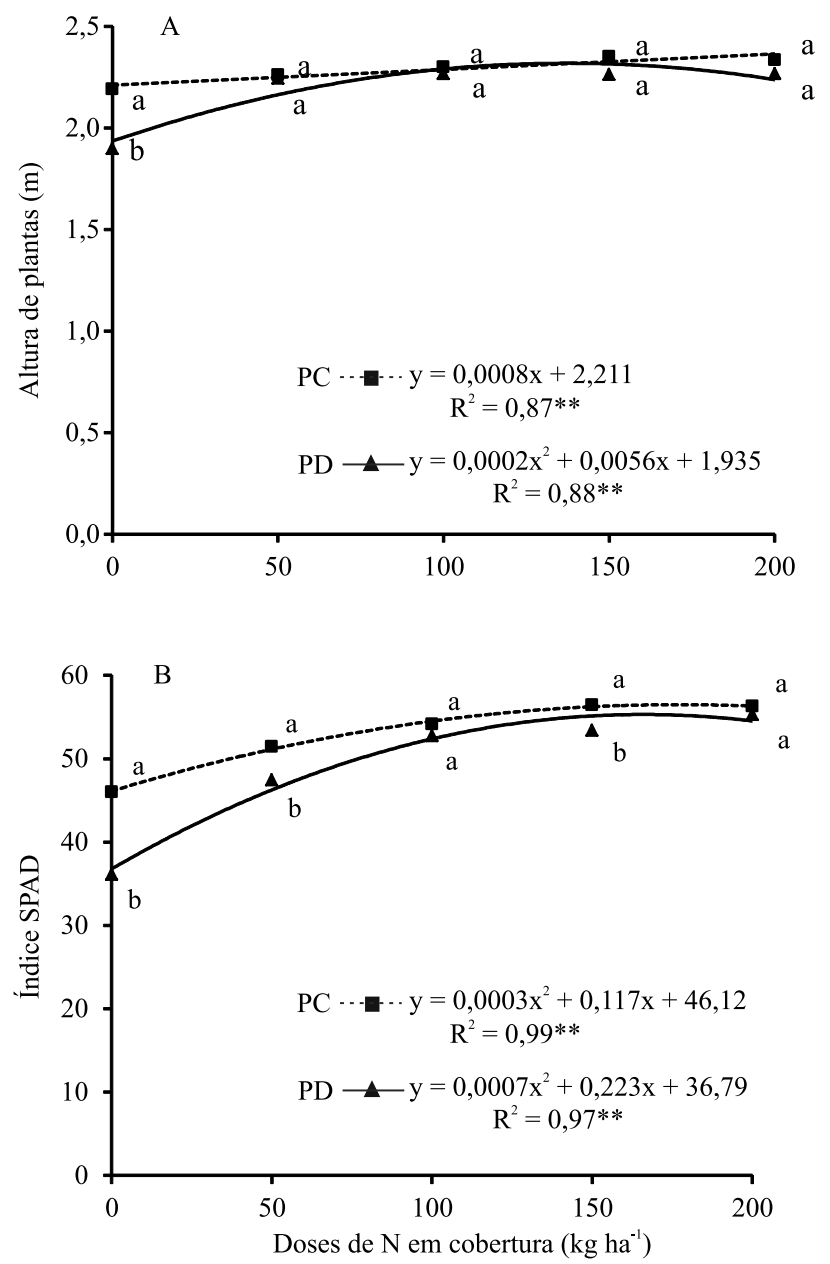

Figura 1. Altura de plantas de milho (A) e índice SPAD (B) em função dos sistemas de manejo do solo, plantio direto (PD) e convencional (PC), e das doses de $\mathrm{N}$ em cobertura, em área agrossilvipastoril, na safra 2012/2013. Médias seguidas de letras iguais, nas doses, não diferem pelo teste $\mathrm{F}$ a $5 \%$ de probabilidade. resíduos vegetais e a mineralização da $\mathrm{MO}$, o que causa maior oferta de $\mathrm{N}$ em curto prazo.

A quantidade de $\mathrm{N}$ disponível no solo está diretamente relacionada ao crescimento das plantas. Segundo Pariz et al. (2011), plantas maiores, além de depositarem maior quantidade de palha no solo após a colheita, apresentam maior acúmulo de nutrientes, os quais serão translocados para as espigas no período de enchimento de grãos, o que pode influenciar diretamente os ganhos de produtividade.

A determinação do teor de clorofila mostrou interação entre os fatores manejo do solo e dose de $\mathrm{N}$ em cobertura (Figura 1). Nos plantios direto e convencional, o maior teor de clorofila foliar foi obtido com a aplicação das doses de 160 e $195 \mathrm{~kg} \mathrm{ha}^{-1}$ de $\mathrm{N}$, o que corresponde à leitura no clorofilômetro de 54,5 e 57,5, respectivamente. Argenta et al. (2003) sugerem que leituras de 58, no clorofilômetro, representam o nível adequado para o estádio de espigamento do milho; portanto, apenas as plantas em solo manejado convencionalmente encontravam-se com níveis satisfatórios de clorofila foliar.

No sistema de manejo convencional do solo com aplicação de quantidade adequada de $\mathrm{N}$ às plantas, $\mathrm{o}$ consórcio da árvore mulateiro e do capim-xaraés não acarretou perdas para as plantas de milho, o que indica que, nesse sistema, a dinâmica de $\mathrm{N}$ é mais eficiente do que no plantio direto. Valores próximos ao observado no presente trabalho foram encontrados por Alves et al. (2013), em cultivo consorciado de milho e braquiária, independentemente da densidade populacional da forrageira na área, o que confirma a não interferência na absorção e no acúmulo de $\mathrm{N}$ pelas plantas de milho. Ao se comparar o plantio direto ao convencional, observou-se menor acúmulo de clorofila foliar no plantio direto, tanto no tratamento controle quanto nas doses de 50 e $150 \mathrm{~kg} \mathrm{ha}^{-1} \mathrm{de} \mathrm{N}$. A possibilidade de haver menor disponibilidade de $\mathrm{N}$ no solo em plantio direto afeta diretamente a quantidade desse nutriente nos tecidos da planta, o que pode influenciar os ganhos de produção.

Para as variáveis produtivas do milho, como número de grãos por fileira (NGF) e número de grãos por espiga (NGE), constatou-se efeito isolado dos fatores manejo do solo e dose de N. Em relação aos manejos do solo, o plantio direto proporcionou menores ganhos (Tabela 1).

Pesq. agropec. bras., Brasília, v.49, n.10, p.762-770, out. 2014 DOI: 10.1590/S0100-204X2014001000003 
Quanto às doses de $\mathrm{N}$ em cobertura, obtiveram-se maior NGF $(29,9)$ e NGE $(536,3)$ com as doses de 136 e $140 \mathrm{~kg} \mathrm{ha}^{-1}$, respectivamente (Figura 2). O NGE é uma variável importante, pois tem relação direta com o potencial produtivo do milho. Quando não há limitações no sistema, o NGE será maior quando houver disponibilidade adequada de $\mathrm{N}$ para as plantas no solo (Soratto et al., 2011), o que resulta em maiores ganhos em produção.

A massa de 100 grãos (M100G) e a massa de grãos por espiga (MGE) apresentaram efeitos isolados dos fatores testados, o que significa que as doses de $\mathrm{N}$ não tiveram relação com os tipos de manejo do solo.

A M100G e a MGE foram superiores no sistema convencional de manejo do solo, em comparação ao plantio direto (Tabela 1). A menor massa obtida no plantio direto pode estar relacionada ao menor teor de $\mathrm{N}$ foliar observado nesse sistema. Essa variável (índice SPAD, Figura 1) apresenta relação com os componentes de produção, uma vez que o $\mathrm{N}$ acumulado nas folhas, durante a fase de floração do milho, influenciará diretamente a fase de enchimento dos grãos (Ferreira et al., 2001).

As doses de 159 e $168 \mathrm{~kg} \mathrm{ha}^{-1}$ de $\mathrm{N}$ em cobertura proporcionaram maior M100G e MGE, de 27,5 e 153,3 g, respectivamente (Figura 2). Resultados superiores foram encontrados por Farinelli \& Lemos (2012), que obtiveram maior M100G (40,1 g) com a dose de $160 \mathrm{~kg} \mathrm{ha}^{-1}$ de N; e por Gomes et al. (2007), que obtiveram maior MGE (183 g) com a dose de $150 \mathrm{~kg} \mathrm{ha}^{-1} \mathrm{~N}$ em cobertura, em área de plantio direto.

A produtividade de grãos de milho foi influenciada pelos sistemas de manejo do solo e pelas doses de $\mathrm{N}$ em cobertura, bem como pela interação entre ambos (Figura 3). No plantio convencional, obteve-se resposta linear crescente à aplicação de $\mathrm{N}$, em que a máxima produtividade observada foi de $7.985 \mathrm{~kg} \mathrm{ha}^{-1}$ com a dose de $200 \mathrm{~kg} \mathrm{ha}^{-1}$ de $\mathrm{N}$ em cobertura. No plantio direto, obteve-se maior produtividade de grãos de $7.342 \mathrm{~kg} \mathrm{ha}^{-1}$ com a dose de $165 \mathrm{~kg} \mathrm{ha}^{-1}$ de N. Ao se comparar os sistemas de manejo do solo, verificou-se diferença entre as produtividades apenas na testemunha e na dose de $150 \mathrm{~kg} \mathrm{ha}^{-1}$ de $\mathrm{N}$, e que estas foram maiores no plantio convencional.

O maior rendimento produtivo obtido com dose elevada de $\mathrm{N}$ em cobertura também foi relatado por Gomes et al. (2007) e Costa et al. (2012), em plantio direto consolidado, e por Farinelli \& Lemos (2012), em plantio convencional, que obtiveram maiores produtividades de grãos de milho com as doses de 150, 166 e $151 \mathrm{~kg} \mathrm{ha}^{-1}$ de $\mathrm{N}$ em cobertura, respectivamente.

$\mathrm{Na}$ área de plantio direto, quando não foi realizada adubação de cobertura, houve redução na produtividade de aproximadamente $2.180 \mathrm{~kg} \mathrm{ha}^{-1} \mathrm{em}$ relação ao plantio convencional. Esse resultado pode ser atribuído à interferência direta das espécies de plantas usadas para a formação e a manutenção da palhada (Macedo, 2009). A eficiência da utilização da adubação nitrogenada em área de plantio direto depende, em grande parte, do tipo de resíduo vegetal em decomposição (Nascimento et al., 2012).

Os resíduos culturais que compõem a palhada utilizada na área experimental foi basicamente do milho safrinha e pelas plantas espontâneas de ocorrência na área, que foram dessecadas. Assim, a alta relação $\mathrm{C} / \mathrm{N}$ existente na palhada do milho, que varia de 46 a 69:1 (Silva et al., 2008; Calonego et al., 2012), a elevada quantidade de material sobre o solo $\left(7,6 \mathrm{Mg} \mathrm{ha}^{-1}\right)$ e a não incorporação do material ao solo contribuíram para a menor eficiência do plantio direto na produção de grãos do tratamento controle. Isso porque, na decomposição da palhada, os microrganismos

Tabela 1. Número de grãos por fileira (NGF), número de grãos por espiga (NGE), massa de 100 grãos (M100G) e massa de grãos por espiga (MGE) de milho, matéria seca das plantas invasoras (MSI) e matéria seca do capim-xaraés (Urochloa brizantha) aos 50, 90 e 145 dias após a colheita do milho (DAC), de acordo com os sistemas de manejo do solo em área agrossilvipastoril, na safra 2012/2013 ${ }^{(1)}$.

\begin{tabular}{|c|c|c|c|c|c|c|c|c|}
\hline \multirow[t]{2}{*}{ Manejo do solo } & \multirow[t]{2}{*}{ NGF } & \multirow[t]{2}{*}{ NGE } & M100G & MGE & \multirow{2}{*}{$\begin{array}{c}\text { MSI } \\
\left(\mathrm{kg} \mathrm{ha}^{-1}\right)\end{array}$} & \multicolumn{3}{|c|}{ Matéria seca do capim-xaraés $\left(\mathrm{kg} \mathrm{ha}^{-1}\right)$} \\
\hline & & & --------- & ----------- & & $50 \mathrm{DAC}$ & $90 \mathrm{DAC}$ & $145 \mathrm{DAC}$ \\
\hline Convencional & $30,3 a * *$ & $535,8 \mathrm{a} *$ & $27,5 \mathrm{a} *$ & $147,8 \mathrm{a}^{* *}$ & $827 \mathrm{a}$ & $1.009 \mathrm{a}$ & $4.930 \mathrm{a}$ & $11.680 \mathrm{a}$ \\
\hline$\underline{\text { Direto }}$ & $27,5 b^{* *}$ & $480,3 b^{*}$ & $25,3 b^{*}$ & $122,4 \mathrm{~b} * *$ & $714 a$ & $668 \mathrm{a}$ & $5.661 \mathrm{a}$ & $10.951 \mathrm{a}$ \\
\hline $\mathrm{CV}(\%)$ & 9,3 & 7,3 & 2,9 & 6,0 & 50,3 & 98,3 & 77,0 & 56,6 \\
\hline
\end{tabular}

${ }^{(1)}$ Médias seguidas de letras iguais, nas colunas, não diferem pelo teste $\mathrm{F}$. * e **Significativo a 5 e $1 \%$ de probabilidade, respectivamente. 
demandam maior quantidade de $\mathrm{N}$ orgânico, o que o torna temporariamente indisponível para as plantas e acarreta menores ganhos de produção nos primeiros anos de cultivo.

De maneira geral, pode-se inferir que o capim-xaraés e o mulateiro não apresentaram competição com a cultura do milho. $\mathrm{O}$ fato de a produtividade do milho não ter sido afetada pelo consórcio com as árvores pode ser justificado pelas características da espécie, que apresenta copa alta, com forma elíptica vertical e densidade rala (Andrade et al., 2012), e pelo extenso espaçamento entre as linhas no sistema, que não promoveram sombreamento excessivo na área.
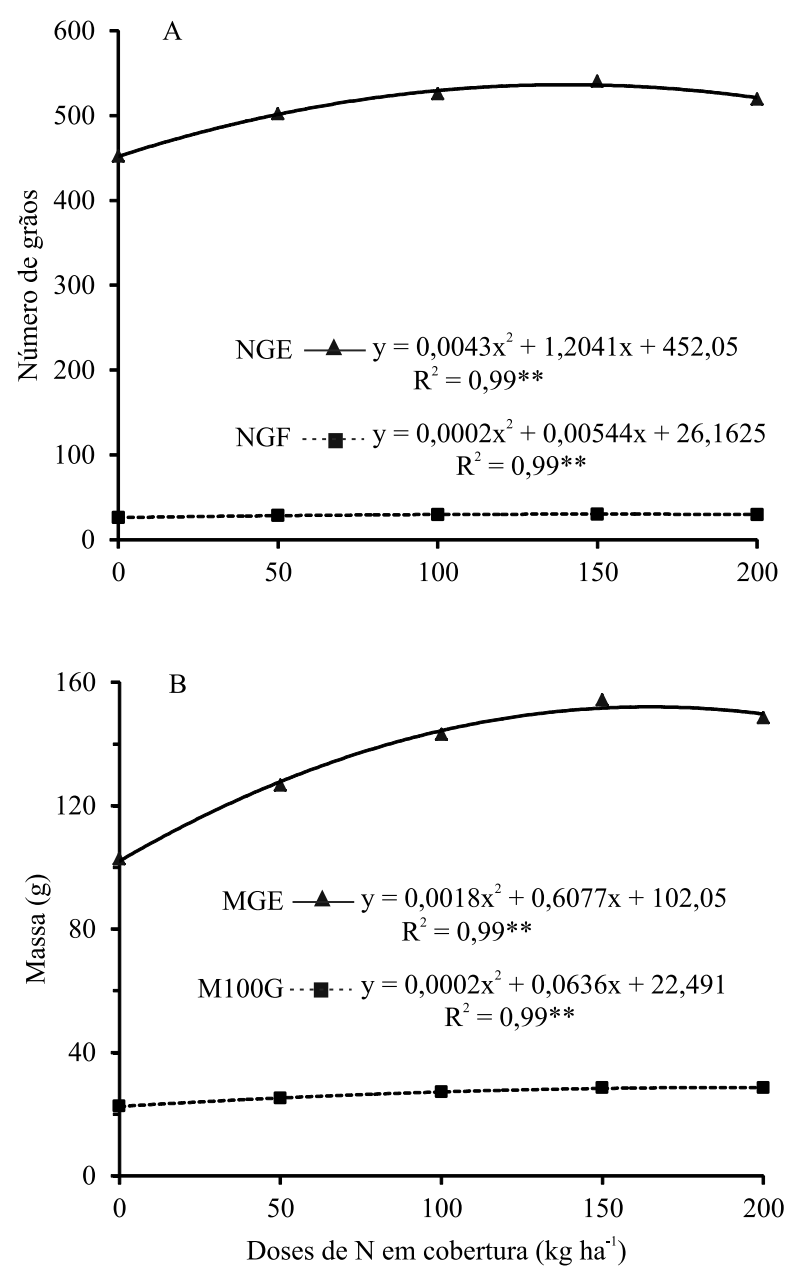

Figura 2. Número de grãos por espiga (NGE), número de grãos por fileira (NGF) (A), massa de grãos por espiga (MGE) e massa de 100 grãos (M100G) de milho (B) em função das doses de $\mathrm{N}$ em cobertura, em área agrossilvipastoril, na safra 2012/2013.
De acordo com Dias-Filho (2011), o cultivo do milho com a espécie arbórea permite incremento na renda em curto prazo e maior tempo para o crescimento das árvores, antes da implantação do pasto e da entrada dos animais. Em relação ao capim-xaraés, há diminuição do poder competitivo da braquiária quando esta é semeada após o milho, pois o maior porte das plantas de milho favorece o sombreamento da entrelinha, o que dificulta o estabelecimento da forrageira (Barducci et al., 2009). Segundo Lara Cabezas (2011), as culturas de maior desenvolvimento vegetativo, como o milho, tendem a inibir o crescimento da pastagem consorciada, o que resulta em menores acúmulos de matéria seca, já que, com o decorrer do período de consórcio com o milho, há um retardamento da maturidade fisiológica da braquiária, resultante do sombreamento excessivo promovido pelas plantas de milho. Após a colheita do milho, a disponibilidade de luz aumenta e o capim se estabelece, o que intensifica o acúmulo de matéria seca (Batista et al., 2011). Além disso, a ocorrência de plantas invasoras também pode contribuir para a supressão da forrageira, principalmente no período de formação da pastagem (Jakelaitis et al., 2010).

Embora não tenha sido evidenciado efeito dos manejos do solo na ocorrência de plantas invasoras, houve acréscimo linear da matéria seca dessas plantas à medida que se aumentou a dose de $\mathrm{N}$ em cobertura, $\mathrm{o}$ que mostra que o N não foi inteiramente disponibilizado

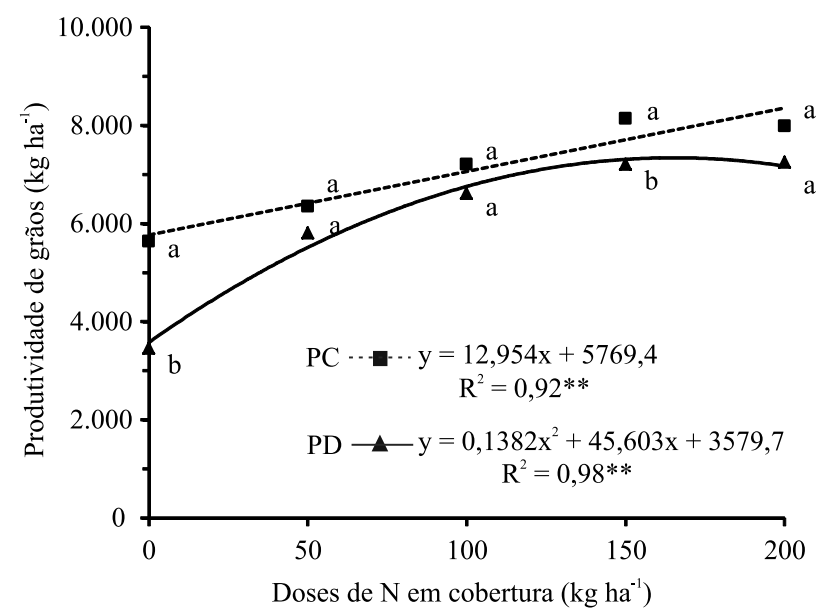

Figura 3. Produtividade de grãos de milho em função dos sistemas de manejo do solo, plantio direto (PD) e convencional (PC), e das doses de $\mathrm{N}$ em cobertura, em área agrossilvipastoril, na safra 2012/2013. Médias seguidas de letras iguais, nas doses, não diferem pelo teste $\mathrm{F}$ a $5 \%$ de probabilidade.

Pesq. agropec. bras., Brasília, v.49, n.10, p.762-770, out. 2014 DOI: $10.1590 / \mathrm{S} 0100-204 \mathrm{X} 2014001000003$ 
para a cultura do milho (Figura 4). Correia et al. (2013) afirmam que a matéria seca de plantas invasoras é maior quando a braquiária é semeada a lanço e sem incorporação, o que justifica a elevada ocorrência de plantas invasoras no momento da colheita do milho.

A agressividade de infestação das plantas invasoras dentro do sistema, entre outros fatores, influenciou o acúmulo de matéria seca do capim-xaraés durante a colheita do milho. Essa variável foi influenciada pelas doses de $\mathrm{N}$ em cobertura na cultura do milho e pela interação destas com os manejos do solo (Figura 5).

A massa da matéria seca do capim-xaraés durante a colheita do milho não foi influenciada pelas doses de $\mathrm{N}$ em cobertura, no plantio convencional. Entretanto, no plantio direto, a maior massa da matéria seca foi obtida quando não foi realizada adubação de cobertura; contudo, com o aumento das doses de N, houve decréscimo na produção de matéria seca, com o mínimo obtido com a dose de $130 \mathrm{~kg} \mathrm{ha}^{-1} \mathrm{de} \mathrm{N}$.

No plantio direto, foram observadas plantas de milho com menor altura na ausência da adubação nitrogenada (Figura 1), condição que favoreceu o desenvolvimento da forrageira, em razão da menor competição estabelecida com as plantas de milho.

Richart et al. (2010) obtiveram baixa produção de matéria seca de $U$. ruziziensis, de $1.007 \mathrm{e}$ $474 \mathrm{~kg} \mathrm{ha}^{-1}$, semeado aos 15 e 30 dias após a implantação do milho, respectivamente. Isso evidencia que as sobressemeaduras tardias prejudicam o

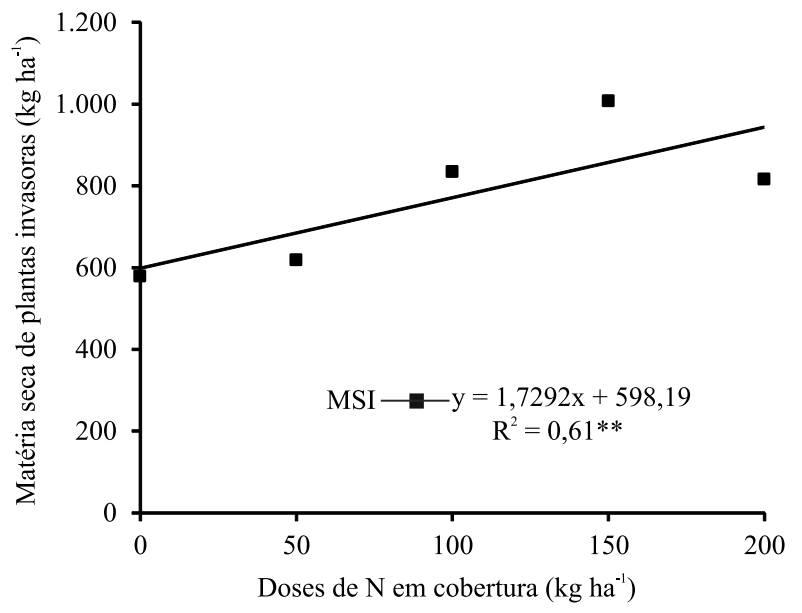

Figura 4. Matéria seca das plantas invasoras (MSI) em função das doses de $\mathrm{N}$ em cobertura na cultura do milho, em área agrossilvipastoril, na safra 2012/2013. desenvolvimento inicial e o acúmulo de massa seca das forrageiras, como observado no presente trabalho.

O acúmulo de matéria seca do capim-xaraés aos 50, 90 e 145 dias após a colheita do milho (DAC) não foi influenciado pelos manejos do solo e pelas doses de $\mathrm{N}$ em cobertura no milho, de forma que não houve ajuste de regressões para explicar a variação dos dados (Tabela 1 e Figura 5). De acordo com Batista et al. (2011), as doses de $\mathrm{N}$ em cobertura na cultura do milho não influenciam o acúmulo de matéria seca
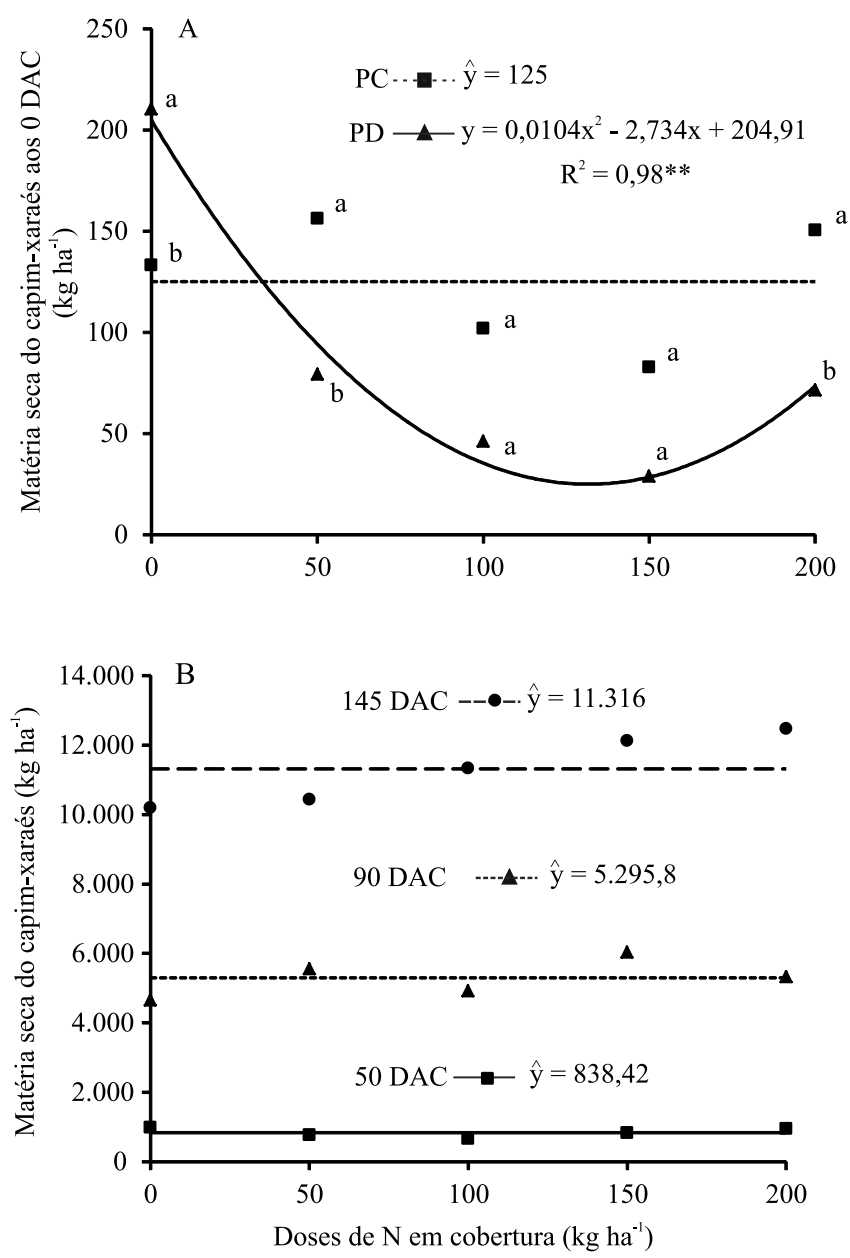

Figura 5. Matéria seca do capim-xaraés (Urochloa brizantha) na colheita do milho ao 0 dias após a colheita (DAC) em função dos sistemas de manejo do solo, plantio direto (PD) e convencional (PC), e das doses de $\mathrm{N}$ em cobertura na cultura do milho (A), e matéria seca do capim-xaraés aos 50, 90 e 145 dias após a colheita do milho (DAC) em função das doses de $\mathrm{N}$ em cobertura na cultura do milho (B), em área agrossilvipastoril, na safra 2012/2013. Médias seguidas de letras iguais, nas doses, não diferem pelo teste $\mathrm{F}$ a $5 \%$ de probabilidade. 
da braquiária, que é mais afetada pela modalidade de consórcio adotada no sistema.

A partir dos $50 \mathrm{DAC}$, os tratamentos controle e as doses de $\mathrm{N}$ em cobertura na cultura do milho em consórcio proporcionaram a mesma produção de matéria seca de capim-xaraés, tendo-se verificado acúmulo diário de matéria seca de aproximadamente $110 \mathrm{~kg} \mathrm{ha}^{-1}$ por dia, com a obtenção de produção satisfatória entre os 90 e 145 DAC (Figura 5).

\section{Conclusões}

1. Em sistema agrossilvipastoril, com a espécie arbórea Calycophyllum spruceanum, em área com plantio convencional do solo, a produtividade de grãos de milho consorciado com capim-xaraés (Urochloa brizantha) responde linearmente à aplicação de $\mathrm{N}$ em cobertura até a dose de $200 \mathrm{~kg} \mathrm{ha}^{-1}$; em área de plantio direto, produtividades satisfatórias são obtidas somente com adubação nitrogenada em cobertura.

2. A adubação nitrogenada em cobertura realizada na cultura do milho até a dose de $200 \mathrm{~kg} \mathrm{ha}^{-1}$ de $\mathrm{N}$ não influencia o rendimento do capim-xaraés em consórcio nas entrelinhas das árvores, após a colheita do milho.

\section{Agradecimentos}

À Embrapa Acre e ao Sr. João Evangelista Ferreira, pelo apoio na condução do experimento; e ao Conselho Nacional de Desenvolvimento Científico e Tecnológico (CNPq), pela bolsa concedida; e ao Banco da Amazônia, pelo apoio financeiro.

\section{Referências}

ACRE. Secretaria de Estado de Meio Ambiente. Zoneamento ecológico-econômico do Acre fase II: documento síntese. Rio Branco: Secretaria de Estado de Planejamento: Secretaria de Estado de Meio Ambiente, 2010. 354p.

ALVES, V.B.; PADILHA, N. de S.; GARCIA, R.A.; CECCON, G. Milho safrinha consorciado com Urochloa ruziziensis e produtividade da soja em sucessão. Revista Brasileira de Milho e Sorgo, v.12, p.280-292, 2013.

ANDRADE, C.M.S. de; SALMAN, A.K.D.; OLIVEIRA, T.K. de (Ed.). Guia arbopasto: manual de identificação e seleção de espécies arbóreas para sistemas silvipastoris. Brasília: Embrapa, 2012. 345p.

ARGENTA, G.; SILVA, P.R.F.; FOSTHOFER, E.L.; STRIEDER, M.L.; SUHRE, E.; TEICHMANN, L.L. Adubação nitrogenada em milho pelo monitoramento do nível de nitrogênio na planta por meio do clorofilômetro. Revista Brasileira de Ciência do Solo, v.27, p.109-119, 2003. DOI: 10.1590/S0100-06832003000100012.
BARDUCCI, R.S.; COSTA, C.; CRUSCIOL, C.A.C.; BORGHI, É.; PUTAROV, T.C.; SARTI, L.M.N. Produção de Brachiaria brizantha e Panicum maximum com milho e adubação nitrogenada. Archivos de Zootecnia, v.58, p.211-222, 2009. DOI: 10.4321/ S0004-05922009000200006.

BATISTA, K.; DUARTE, A.P.; CECCON, G.; DE MARIA, I.C.; CANTARELLA, H. Acúmulo de matéria seca e de nutrientes em forrageiras consorciadas com milho safrinha em função da adubação nitrogenada. Pesquisa Agropecuária Brasileira, v.46, p.1154-1160, 2011. DOI: 10.1590/S0100-204X2011001000006.

BORGHI, E.; CRUSCIOL, C.A.C. Produtividade de milho, espaçamento e modalidade de consorciação com Brachiaria brizantha em sistema plantio direto. Pesquisa Agropecuária Brasileira, v.42, p.163-171, 2007. DOI: 10.1590/ S0100-204X2007000200004.

CALONEGO, J.C.; GIL, F.C.; ROCCO, V.F.; SANTOS, E.A. dos. Persistência e liberação de nutrientes de palha de milho, braquiária e labe-labe. Bioscience Journal, v.28, p.770-781, 2012.

CHIODEROLI, C.A.; MELLO, L.M.M. de; HOLANDA, H.V. de; FURLANI, C.E.A.; GRIGOLLI, P.J.; SILVA, J.O. da R.; CESARIN, A.L. Consórcio de Urochloas com milho em sistema plantio direto. Ciência Rural, v.42, p.1804-1810, 2012. DOI: $10.1590 / \mathrm{S} 0103-84782012005000073$.

CORREIA, N.M.; LEITE, M.B.; FUZITA, W.E. Consórcio de milho com Urochloa ruziziensis e os efeitos na cultura da soja em rotação. Bioscience Journal, v.29, p.65-76, 2013.

COSTA, N.R.; ANDREOTTI, M.; GAMEIRO, R. de A.; PARIZ, C.M.; BUZETTI, S.; LOPES, K.S.M. Adubação nitrogenada no consórcio de milho com duas espécies de braquiária em sistema plantio direto. Pesquisa Agropecuária Brasileira, v.47, p.1038-1047, 2012. DOI: 10.1590/S0100-204X2012000800003.

DIAS-FILHO, M.B. Os desafios da produção animal em pastagens na fronteira agrícola brasileira. Revista Brasileira de Zootecnia, v.40, p.243-252, 2011. Suplemento especial.

FARINELLI, R.; LEMOS, L.B. Nitrogênio em cobertura na cultura do milho em preparo convencional e plantio direto consolidados. Pesquisa Agropecuária Tropical, v.42, p.63-70, 2012. DOI: 10.1590/S1983-40632012000100009.

FERREIRA, A.C. de B.; ARAÚJO, G.A. de A.; PEREIRA, P.R.G.; CARDOSO, A.A. Características agronômicas e nutricionais do milho adubado com nitrogênio, molibdênio e zinco. Scientia Agricola, v.58, p.131-138, 2001. DOI: 10.1590/ S0103-90162001000100020.

FERREIRA, D.F. Sisvar: a computer statistical analysis system. Ciência e Agrotecnologia, v.35, p.1039-1042, 2011. DOI: 10.1590/S1413-70542011000600001.

FRANZLUEBBERS, A.J. Integrated crop-livestock systems in the Southeastern USA. Agronomy Journal, v.99, p.361-372, 2007. DOI: 10.2134/agronj2006.0076.

GOMES, R.F.; SILVA, A.G. da; ASSIS, R.L. de; PIRES, F.R. Efeito de doses e da época de aplicação de nitrogênio nos caracteres agronômicos da cultura do milho sob plantio direto. Revista Brasileira de Ciência do Solo, v.31, p.931-938, 2007. DOI: 10.1590/S0100-06832007000500010. 
JAKELAITIS, A.; GIL, J. de O.; SIMÕES, L.P.; SOUZA, K.V. de; LUDTKE, J. Efeito da interferência de plantas daninhas na implantação de pastagem de Brachiaria brizantha. Revista Caatinga, v.23, p.8-14, 2010.

LARA-CABEZAS, W.A.R. Manejo de gramíneas cultivadas em forma exclusiva e consorciada com Brachiaria ruziziensis e eficiência do nitrogênio aplicado em cobertura. Revista Milho e Sorgo, v.10, p.130-145, 2011.

MACEDO, M.C.M. Integração lavoura e pecuária: o estado da arte e inovações tecnológicas. Revista Brasileira de Zootecnia, v.38, p.133-146, 2009. DOI: 10.1590/S1516-35982009001300015.

NASCIMENTO, F.M.; BICUDO, S.J.; FERNANDES, D.M.; RODRIGUES, G.L.; FERNANDES, J.C.; FURTADO, M.B. Doses e épocas de aplicação de nitrogênio: influência na relação $\mathrm{C} / \mathrm{N}$ da palhada no desenvolvimento e produtividade do milho em sistema plantio direto. Científica, v.40, p.77-89, 2012.

PARIZ, C.M.; ANDREOTTI, M.; AZENHA, M.V.; BERGAMASCHINE, A.F.; MELLO, L.M.M. de; LIMA, R.C. Produtividade de grãos de milho e massa seca de braquiárias em consórcio no sistema de integração lavoura-pecuária. Ciência Rural, v.41, p.875-882, 2011. DOI: 10.1590/S0103-84782011000500023.

RICHART, A.; PASLAUSKI, T.; NOZAKI, M. de H.; RODRIGUES, C.M.; FEY, R. Desempenho do milho safrinha e da Brachiaria ruziziensis cv. Comum em consórcio. Revista Brasileira de Ciências Agrárias, v.5, p.497-502, 2010. DOI: 10.5039/agraria.v5i4a855.
SECAGEM de sementes. Brasília: Associação Brasileira de Educação Agrícola Superior, 1987. 37p.

SILVA, E.C. da; MURAOKA, T.; BUZETTI, S.; ESPINAL, F.S.C.; TRIVELIN, P.C.O. Utilização do nitrogênio da palha de milho e de adubos verdes pela cultura do milho. Revista Brasileira de Ciência do Solo, v.32, p.2853-2861, 2008. DOI: 10.1590/S010006832008000700032.

SORATTO, R.P.; SILVA, Â.H. da; CARDOSO, S. de M.; MENDONÇA, C.G. de. Doses e fontes alternativas de nitrogênio no milho sob plantio direto em solo arenoso. Ciência e Agrotecnologia, v.35, p.62-70, 2011. DOI: 10.1590/S141370542011000100007.

TRACY, B.F.; ZHANG, Y. Soil compaction, corn yield response, and soil nutrient pool dynamics within an integrated crop-livestock system in Illinois. Crop Science, v.48, p.1211-1218, 2008. DOI: 10.2135/cropsci2007.07.0390.

VIEIRA, M.; SCHUMACHER, M.V. Biomassa em povoamentos monoespecíficos e mistos de eucalipto e acácia-negra e do milho em sistema agrosilvicultural. Cerne, v.17, p.259-265, 2011. DOI: 10.1590/S0104-77602011000200014.

VILELA, L.; MARTHA JUNIOR, G.B.; MACEDO, M.C.M.; MARCHÃO, R.L.; GUIMARÃES JÚNIOR, R.; PULROLNIK, K.; MACIEL, G.A. Sistemas de integração lavoura-pecuária na região do Cerrado. Pesquisa Agropecuária Brasileira, v.46, p.1127-1138, 2011. DOI: 10.1590/S0100-204X2011001000003.

Recebido em 29 de abril de 2014 e aprovado em 17 de setembro de 2014 